\title{
تصورات معلمات العلوم قبل الخدمة للنماذج العلمية
}

\author{
سناء محمد ابوعاذره
}

استاذ مشارك في المناهج وطرق تدريس العلوم- كلية التربية- جامعة الطائف- السعودية sa37003@yahoo.com 


\title{
تصورات معلمات العلوم قبل الخدمة للنماذج العلمية
}

\author{
سناء محممد ابوعاذره \\ استاذ مشارك في المناهج وطرق تدريس العلوم- كلية التربية- جامعة الطائف- السعودية \\ sa37003@yahoo.com
}

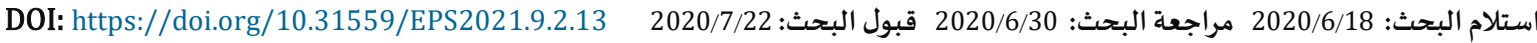

\begin{abstract}
هدفت هذه الدراسة إلى الكشف عن تصورات معلمات العلوم قبل الخدمة للنماذج العلمية، وتكونت عينة الدراسة من (78) معلمة من معلمات العلوم قبل الخدمة الملتحقات ببرنامج الدبلوم التربوي في جامعة الطائف للفصل الدراسي الاول للعام 2018-2019 ، ولتحقيق غرض المان الدراسة استخدمت الباحثة المنهج الوصفي، وقد تم تصميم أستبانة كأداة لتطبيق ألدراسة، وقد توصلت التهات نتائج الدراسة إلى أن تصورات معلمات العلوم قبل الخدمة للنماذج العلمية جاءت بمستوى مرتفع، وكما أشـارت النتائج الى عدم وجود فروق ذات دلالية إحصائية عند

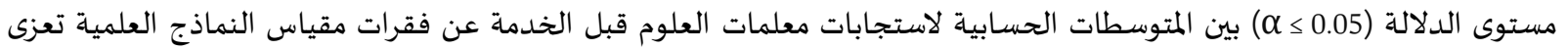
لمتغير التخصص، وأوصت الدراسة بتوجيه القائمين على البرامج التدريبية للمعلمين في قطاع التعليم بإعداد برامج تدريبية حول كيفية بناء وتقييم النماذج العلمياة.

الكلمات المفتاحية: تصورات؛ معلمات العلوم؛ قبل الخدمة؛ النماذج العلمية.
\end{abstract}

تلعبُ النّماذج الْعلمية دورًا مركزيًا في تعليمِ العلومِ، ويتطلبُ إدخال النّماذج بنجاحِ في تدريسِ الْعلوم أن يكونَ لدى الْمعلمين فهم ومعرفة بأهمية

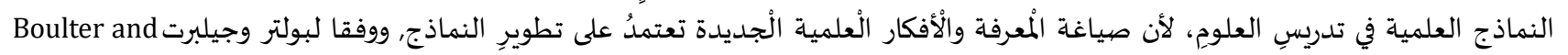

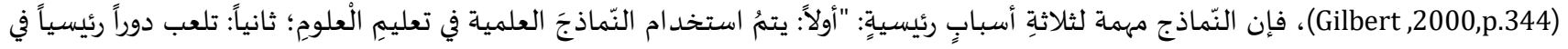
طبيعة العلم وإنجازاته؛ وثالثاً: تلعب دوراً رئيسياً في التكنولوجيا ".

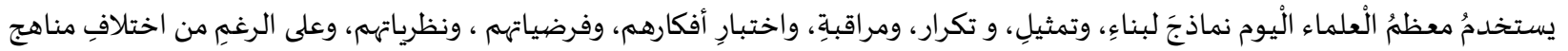

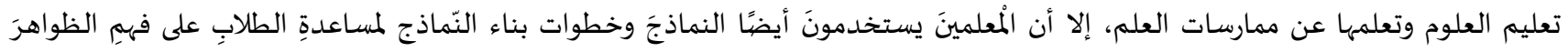

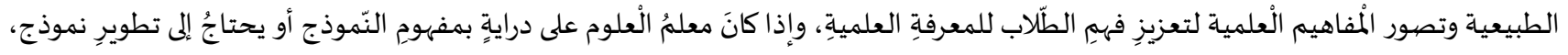

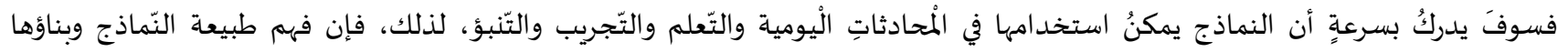
واستخد امها في تدريسِ العلومِ والتعلم هو جوهر مناهج العلوم (Oh \& Oh,2011, Gilbert \& Ireton,2003 ).

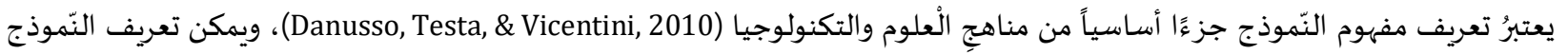

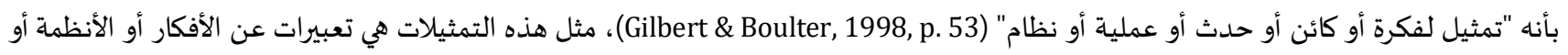

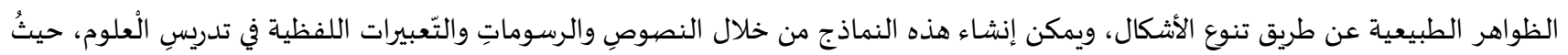

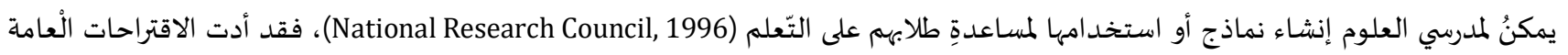

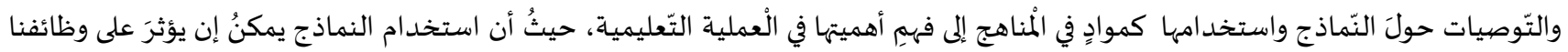
الْمعرفية؛؛ مما أسفر عن شكلٍ جديلٍٍ من التفكيرِ المعروف باسم "التفكير القائم على ألنموذجي" (Magnani \& Nersessian, 2002). 


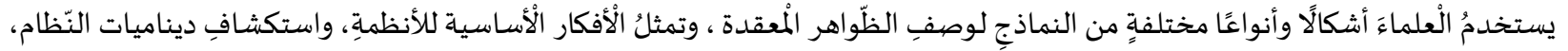

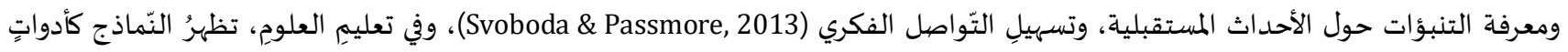

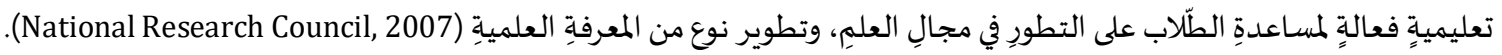

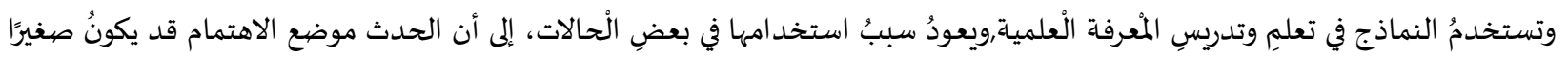

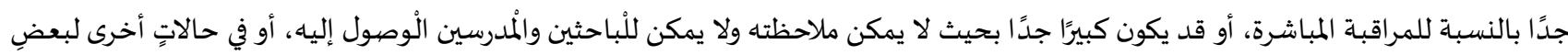

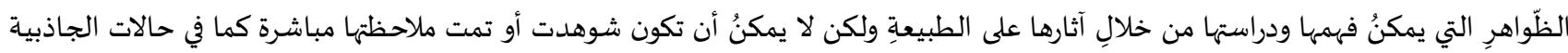

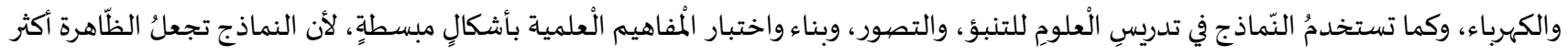

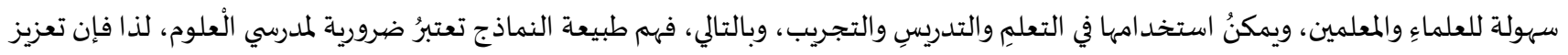

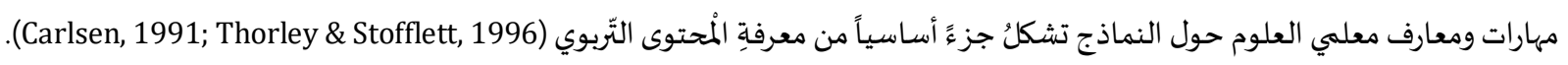

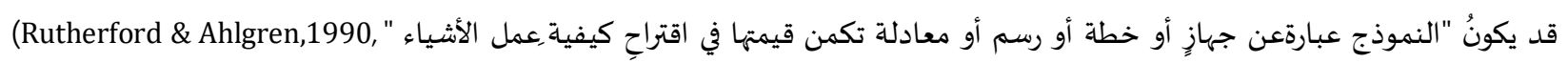

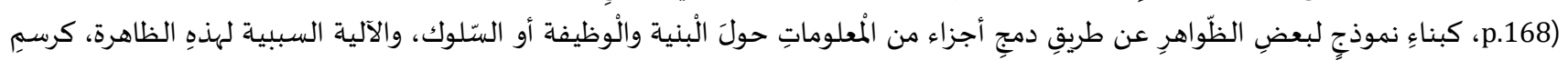

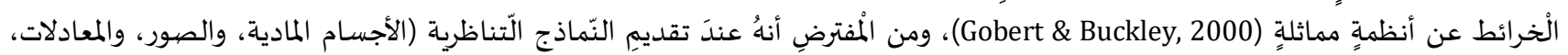

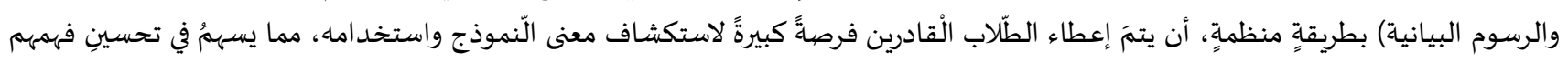

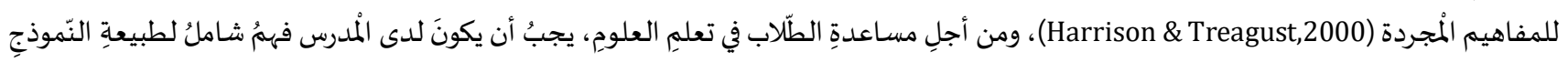

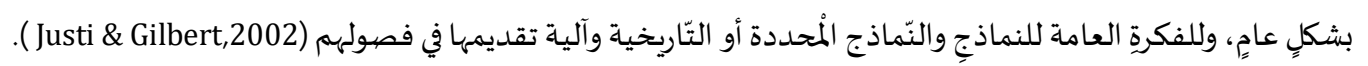

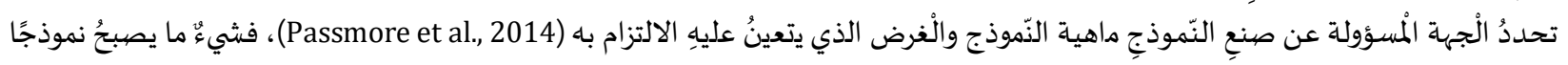

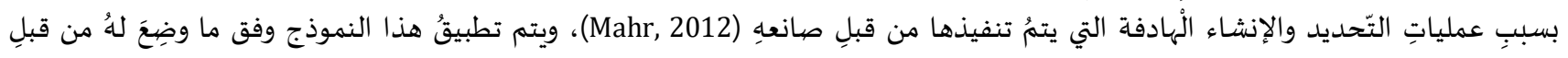

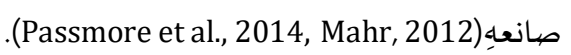
النّماذج الْعلمية لها دورٌ مؤكدّ في البحثِ العلمي، وكذلكَ في تعليمِ العلوحِ (Halloun, 2007; Justi \& Gilbert, 2002)، ورغم وجود تعريفات

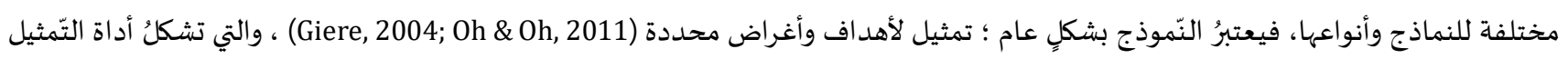

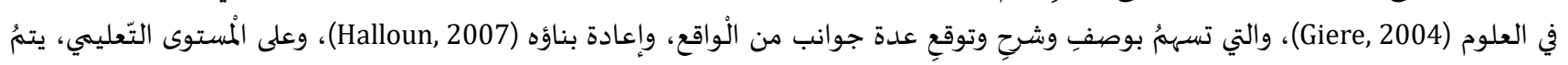

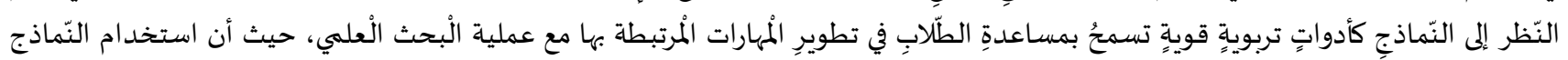

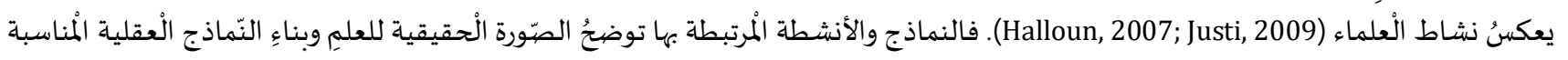

. (Koponen,2007; Oh \& Oh, 2011)

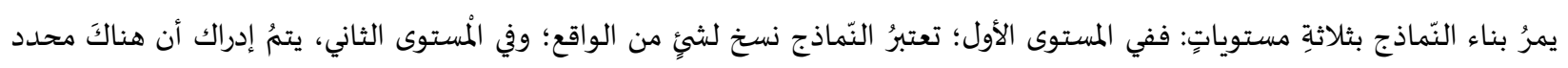

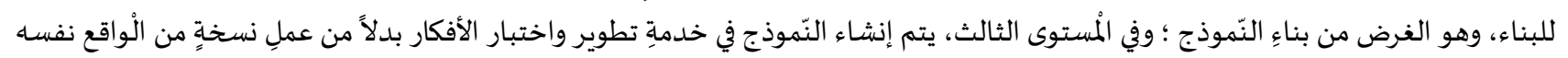
(Grosslight et al. ,1991)

إن استخدام النّماذج الْعلمية في محاكاة الْعمليات والظواهرِ الطُّبيعية له أهمية في تطويرِ التّعلم والتّفسير والاستدلال (Bolacha et al., 2012)،

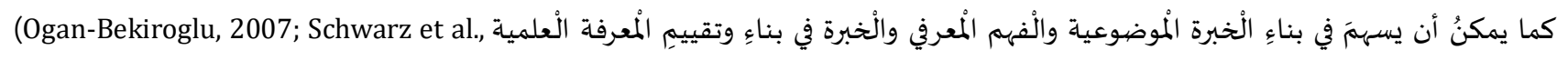

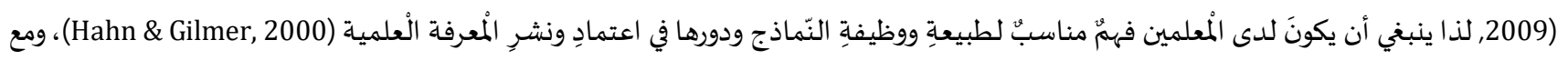

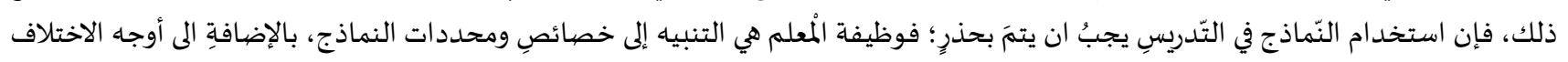

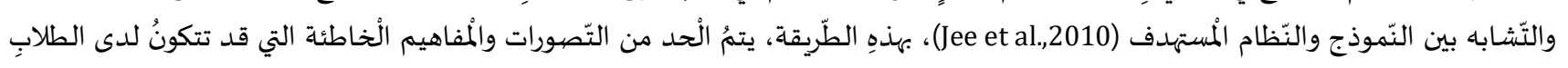
نتيجة استخدام النماذجَ في التدريسِ.

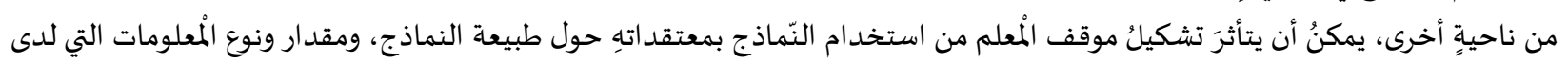

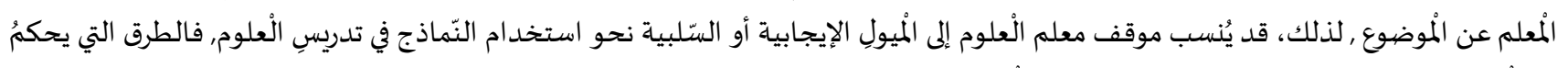

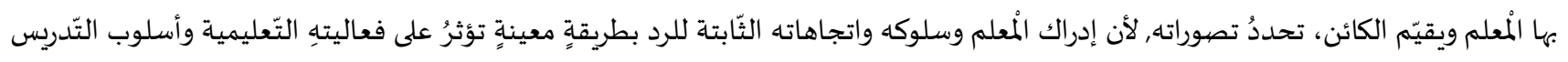

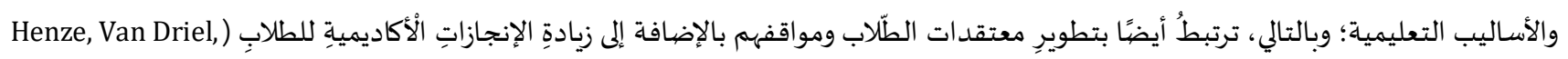

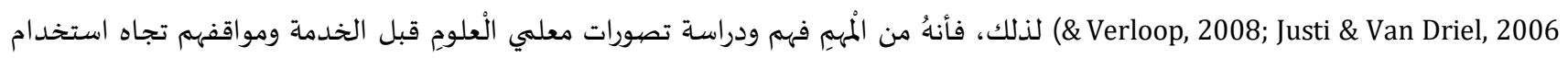
النماذج الْعلمية. 
الدراسات السابقة:

بمراجعةِ الْأدب التّربوي نجدُ بعض الدّراسات التي قيمت معرفة معلمي الْعلوم للنماذج الْعلمية،

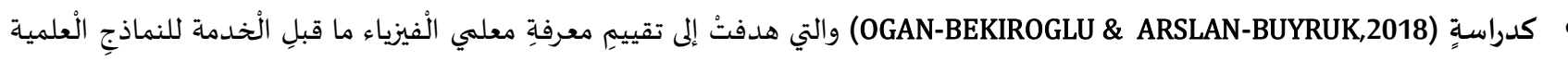

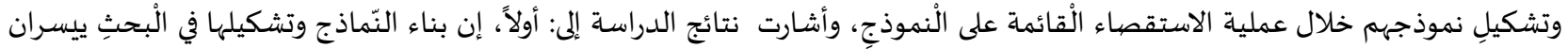

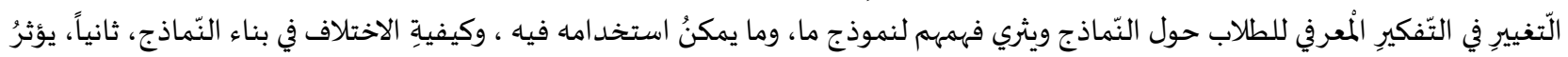

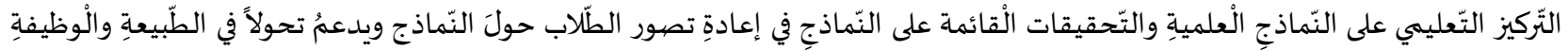

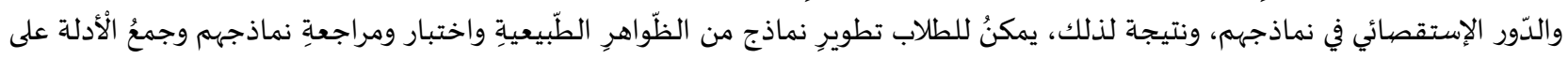

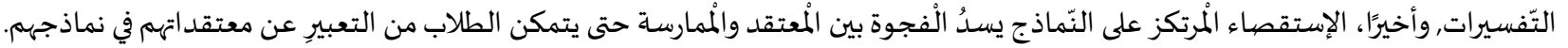

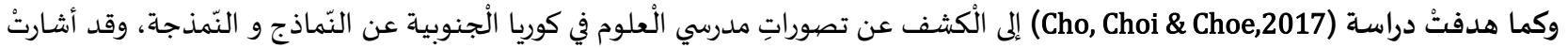

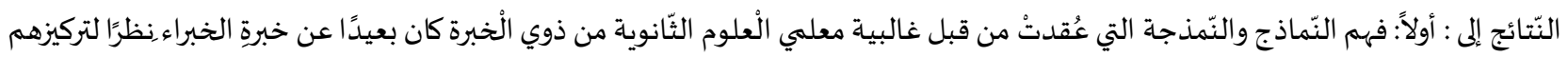

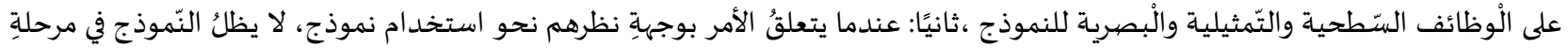

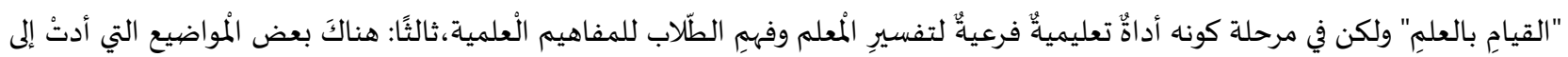

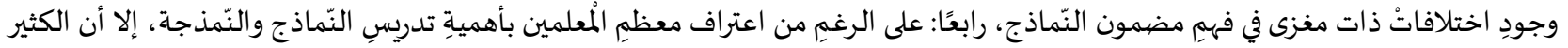

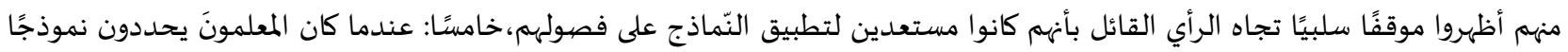

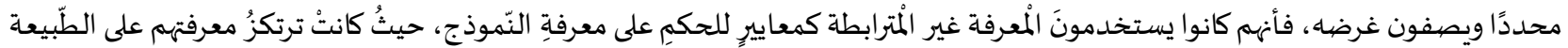

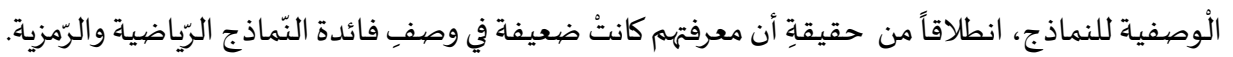

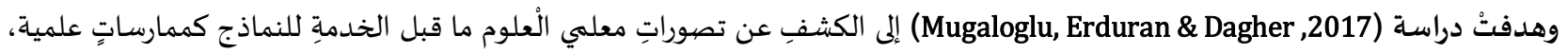

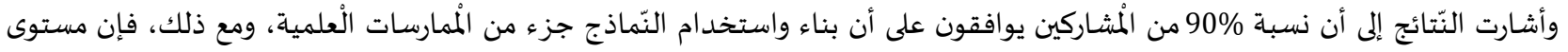

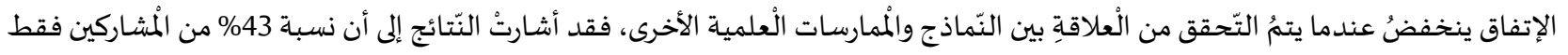

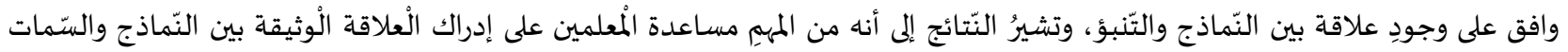

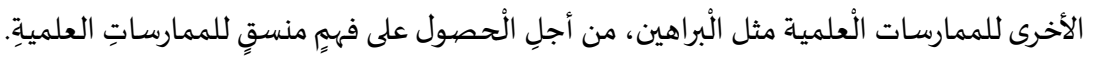

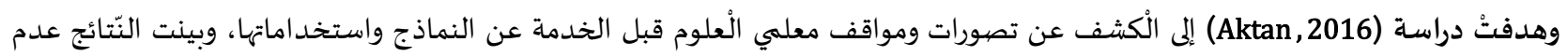

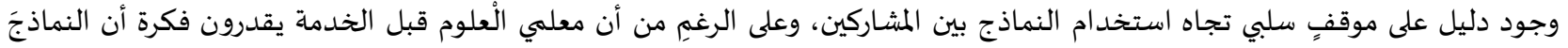

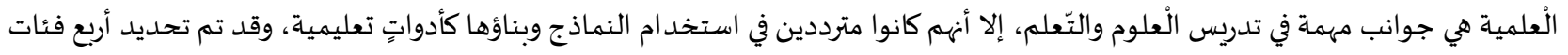

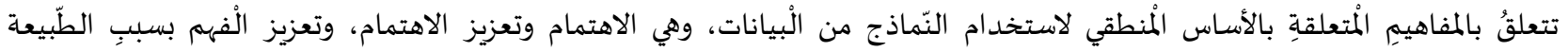

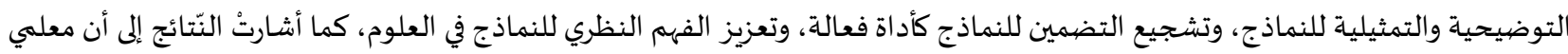

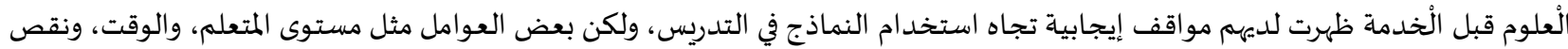

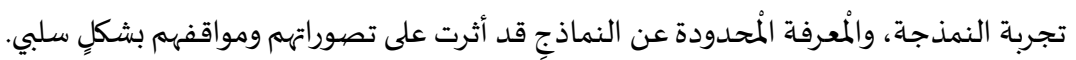

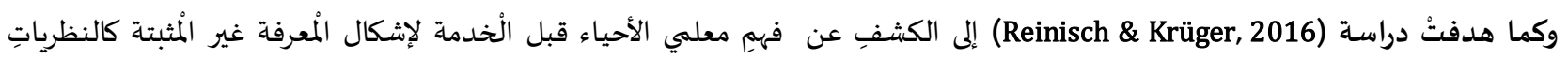

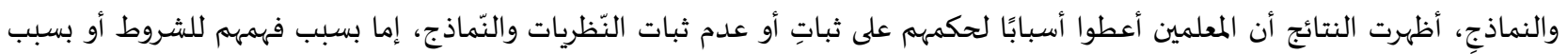

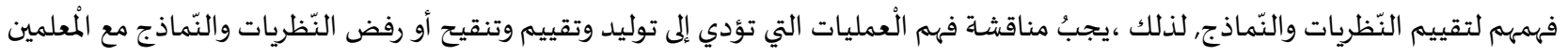

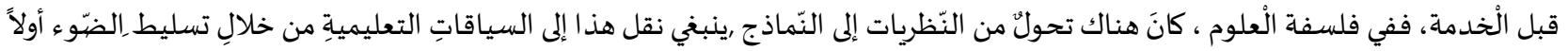
على دورِ النماذج وأيضاً ارتباطها بالنظرياتِ.

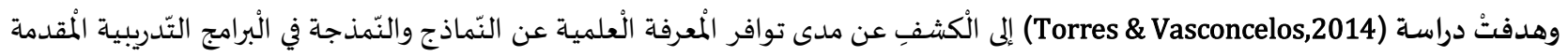

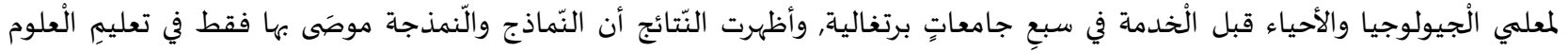

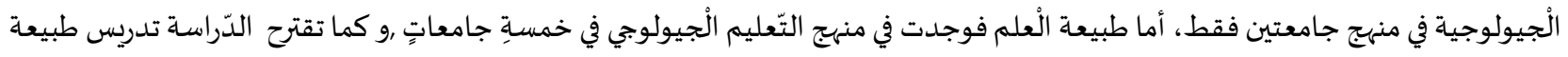

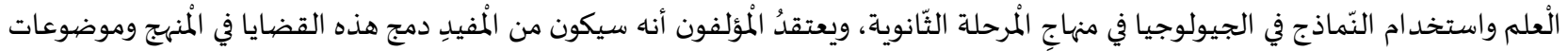
تعليم الْجيولوجيا في تدريبِ الْمعلمين.

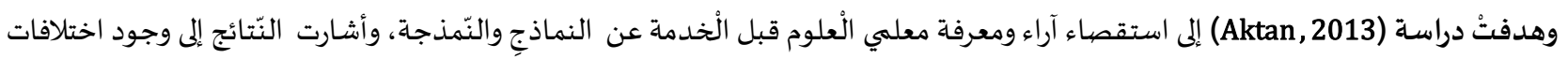

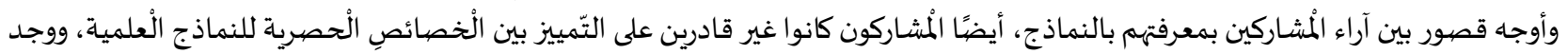

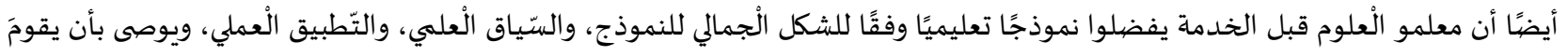


معلمو الْعلوم قبل الخدمة بالإنخراط في الْمزيد من أنشطة النّمذجة واكتساب المُزيد من الْخبرات طوال حياتهم من خلال برامج تدريبية لتحسين معرفتهم بالمحتوى للنماذج والنمذجة. وهدفتُ دراسـة (Nelson \& Davis , 2012) إلى التّعرف على قدرة معلمي الْعلوم قبل الْخدمة للمرحلِِ الابتدائيةِ على تقييمِ عمل الطّلاب للنماذج

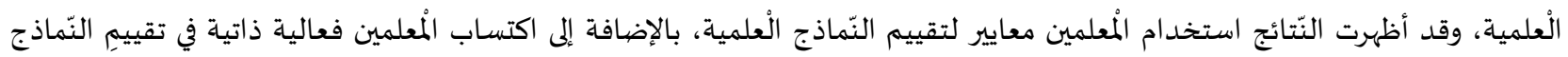

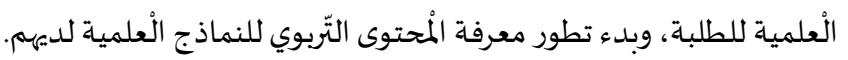
هدفتُ دراسـة (Gobert \& et al.,2011) إلى الكشفِ عن العلاقِة بين فهم الطّلاب لطبيعة النماذج والتعلم المفاهيمي في علمِ الأحياء، والفيزياء،

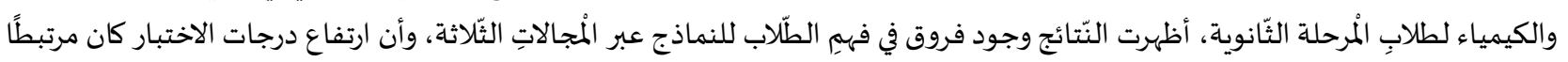
بعددٍ أكبر من الأنشطِة المنهجيةِ. وكما هدفتُ دراسة (Justi \& Gilbert,2002) إلى الكشفِ عن معرفة معلمي الْعلوم تجاه استخدام النماذج والنمذجة في في تعليم العلوم على

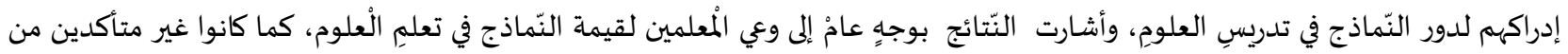

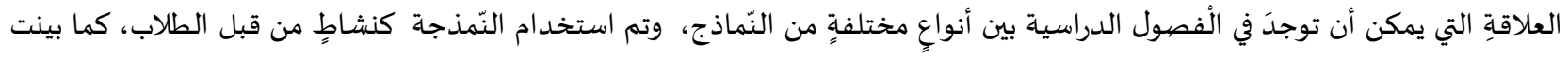

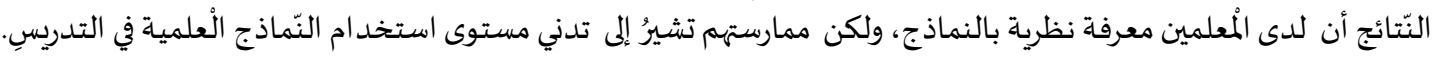

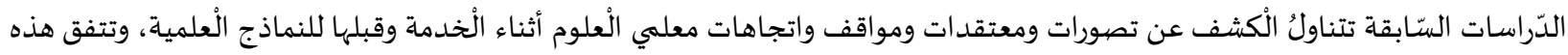

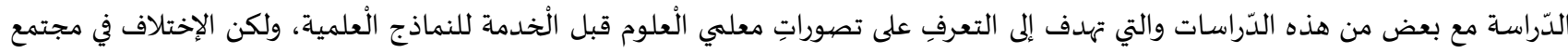

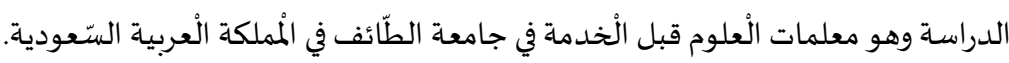

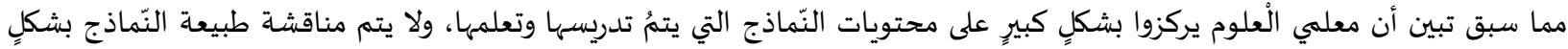

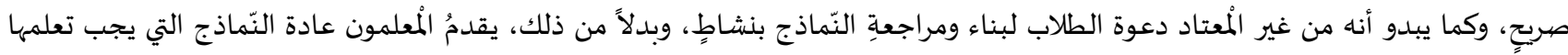

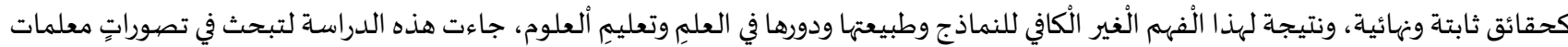
الْعلوم قبل الْخدمة للنماذج الْعلمية.

مشكلة الدراسـة:

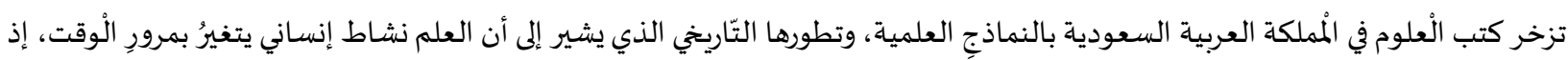

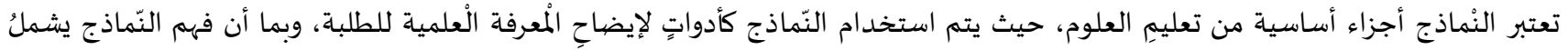

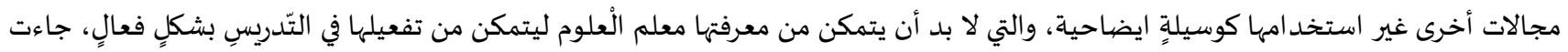

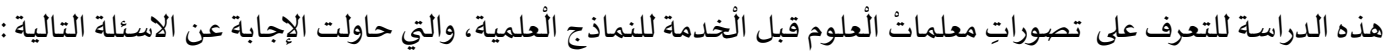

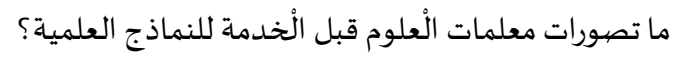

هل هناك فروق ذات دلالة إحصائية في تصورات معلمات الْعلوم قبل الْخدمة للنماذج الْعلمية تعزى للتخصص في درجة البكالوريوس؟

فروض الدراسة:

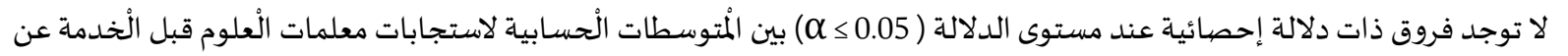

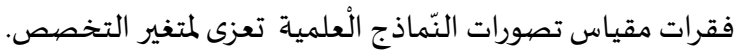

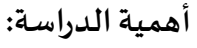
تكمن أهمية هذه الدراسة في الموضوعِ الذي تتناوله، وهو التّعرف على تصورات معلمات الْعلوم قبل الْخدمة للنماذج الْعلمية، حيث من الْمكن

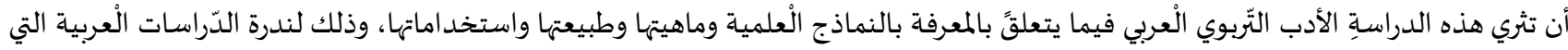

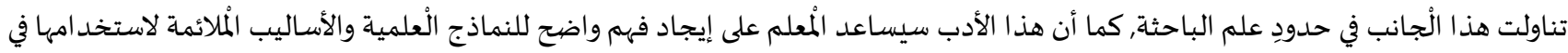

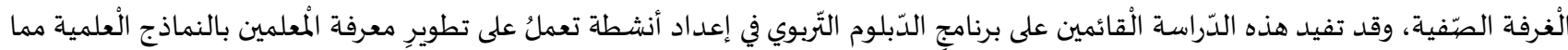

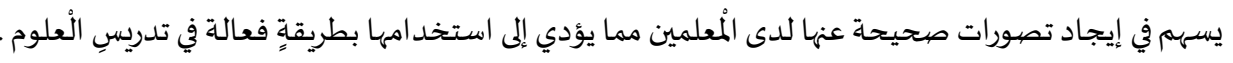

حدود الدراسـة:

اقتصرت الدّراسة على معلماتِ الْعلوم قبل الخدمة في برنامجِ الّّدبلوم التّربوي في جامعِِ الطائف للفصل الدّراسي الأول للعام 2018-2019 . اقتصرت الدّراسة على أداة الدّراسة وهي استبيان لقياسِ تصورات معلمات الْعلوم قبل الْخدمة للنماذج الْعلمية. 
مصطلحات الدراسة:

معلمات الْعلوم قبل الْخدمة: هن طالبات الْعلوم في تخصصياتِ الأحياء والكيمياء والفيزياء الْلتحقات ببرنامجِ الدّبلوم التّربوي في جامعِِ الطّائف في

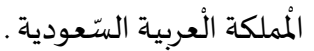
النّماذج الْعلمية: هي تمثيل لنظامِ أو كائن أو فكرة تنبثق من أحد جوانب الْمعرفة الْعلمية لتعزيز فهمه بشكل أفضل. الطربقة والإجراءات: منهج الدراسة: اتبع الْبحث الْحالي الْنههج الْوصفي التّحليلي حيث يقوم هذا البحث على وصفِ ظاهرة والتعبير عنها كميًا ووصفيًا. مجتمع الدراسـة وعينتها: تكون مجتمع الدراسة من جميع طالبات برنامج الّدبلوم التّربوي في تخصصِ الْعلوم قبل الْخدمة في كليةِ التربية في جامعِِ الطائف في المملكة العربية السعودية , وبلغ عددهن (217) طالبة في الْفصل الأول من الْعام الدراسي 2018-2019 ، وتم اختيار عينة الدّراسـة من مجتمع الدراسة بطريقة قصدية حيث تكونت عينة الدراسـة من (78) طالبة .

أداة الدراسـة: ;Cho, Choi \& Choe,2017; OGAN-BEKIROGLU \& ARSLAN-) تم بناء أداة الدراسة من خلال الإستعانة باالدراسات السابقة

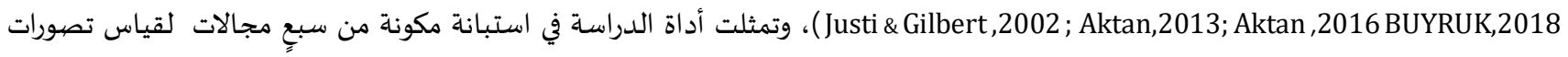

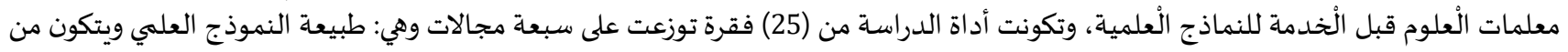

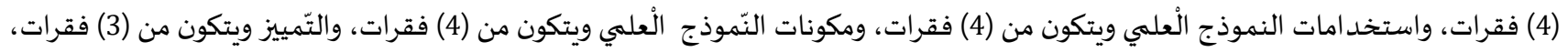

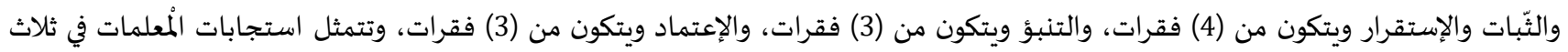

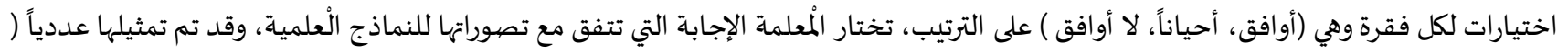

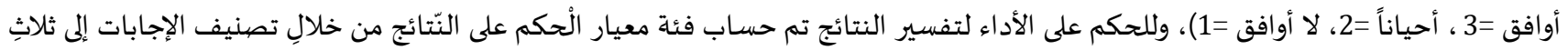

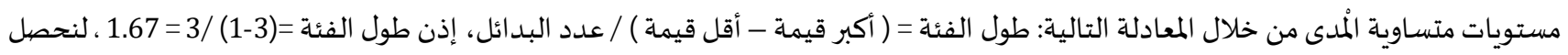
على مدى المتوسطات التالية : ملئ جدول (1): مدى المتوسطات للحكم على الاداء

\begin{tabular}{|c|c|c|c|}
\hline ضعيف & متوسط & مرتفع & مستوى المممارسة \\
\hline $1.66-1$ & $2.33-1.67$ & $3-2.34$ & مدى المتوسطات \\
\hline
\end{tabular}

صبدق الأداة:

استخدمت الباحثة طريقتين للتأكد من صددق الأداة: أولاً: صبدق المحكمين:

تحققت الباحثة من صدق الأداة عن طريق عرض الأداة على سبعة متخصصين في المناهج وطرق تدريس العلوم، وذلك لإبداء ملاحظاتهم حول مدى ملائمة فقرات الأداة، واقتراح ما يرونه مناسباً من تعديلات، وفي ضوء ادواء اراء ومقترحات المحكمين تم إجراء بعض التعديلات للصياغة اللغوية والتنسيق.

ثانياً: صدق الاتساق الداخليق: تم إيجاد صدق الاتساق الداخلي بتطبيق الأداة على عينة استطلاعية تكونت من (30) طالبة من مجتمع الدراسـة، وخارج عينة الدراسـة، وتم

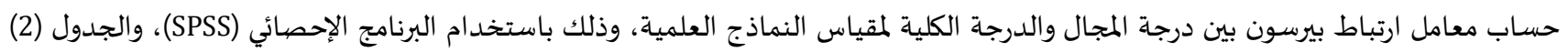
يوضح ذلك: 


\begin{tabular}{|c|c|c|}
\hline معامل الإرتباط & المجالات & 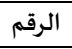 \\
\hline $0.703^{* *}$ & طبيعة النموذج العلمي & 1 \\
\hline $0.793^{* *}$ & استخدامات النموذج العلمي & 2 \\
\hline $0.605^{* *}$ & مكونات النموذج العلمي & 3 \\
\hline $0.513^{* *}$ & التمييز & 4 \\
\hline $0.718^{* *}$ & الثبات والاستقرار & 5 \\
\hline $0.575^{* *}$ & 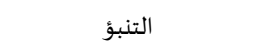 & 6 \\
\hline $0.757^{* *}$ & الاعتماد & 7 \\
\hline
\end{tabular}

(0.01) قيمة معامل الارتباط دال عند مستوى (**)

يتضح من الجدول (2) أن جميع قيم معاملات ارتباط المجالات بالدرجة الكلية للمقياس دالة إحصائياً عند مستوى دلالة (0.01)، وفي ضوء هذه

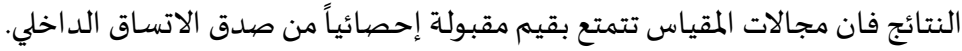
ثبات الأداة:

للتحقق من ثبات الأداة تم تطبيقها على عينٍة استطلاعية تكونت من (30) طالبة من مجتمع الدراسة، وخارج عينة الدراسـة، وقد تم استخدام

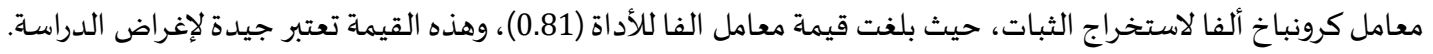

المعالجة الاحصيائية

للإجابة عن أسئلة الدراسة تم استخدام الحزمة الإحصائية في العلوم الاجتماعية (SPSS) لحساب معامل ارتباط بيرسون، وحساب المتوسطات الحسابية والانحرافات المعيارية للفقرات، والمجال، وكما تم استخدام اختبار كروسكال والس.

نتائج الدراسـة ومناقشتها:

السّؤال الأول: للإجابة عن سؤال الدّراسة الأول الذي نصهه "ما تصورات معلمات الْعلوم قبل الْخدمة للنماذج العلمية؟ " تم تطبيق استبيان

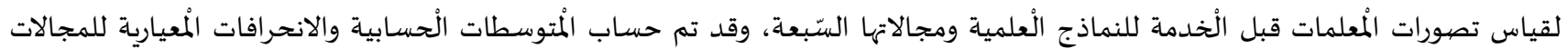

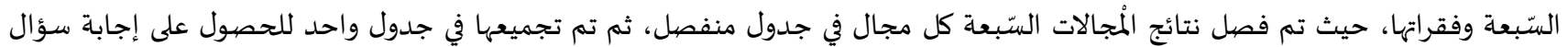
ويمثل الجدول (3) الْمتوسطات الْحسابية والإنحرافات الْمعيارية لاستجابات معلمات العلوم قبل الخدمة على فقرات المجال الأول طبيعة النموذج

جدول (3): المتوسطات الحسابية والانحر افات المعيارية لاستجابات معلمات العلوم قبل الخدمة على فقرات المجال الأول طبيعة النموذج العلمي

\begin{tabular}{|c|c|c|c|c|}
\hline 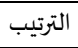 & الانحراف المعياري & المتوسط الحسابي & 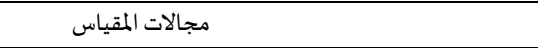 & 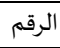 \\
\hline 4 & 0.859 & 2.256 & يمثل النموذج العلمي استنساخ لشيء ما. . ي & 1 \\
\hline 2 & 0.776 & 2.384 & يمثل النموذج العلمي ما يحدث في ظاهرة معينة تمثيلا كاملا. & 2 \\
\hline 3 & 0.696 & 2.333 & يمثل النموذج العلمي ما يحدث في ظاهرة معينة تمثيلا جزئيا. & 3 \\
\hline \multirow[t]{2}{*}{1} & 0.697 & 2.525 & يمثل النموذج العلمي صهوره ذهنية . & 4 \\
\hline & 0.757 & 2.375 & المجموع & \\
\hline
\end{tabular}

نلاحظ من الجدول (3) أن معرفة معلمات العلوم قبل الخدمة بمجال طبيعة النموذج العلمي جاء بمستوى مرتفع، حيث بلغ المتوسط الحسابي

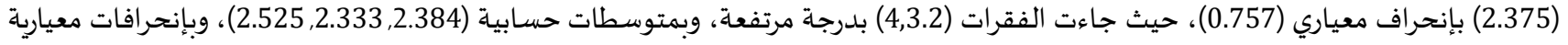

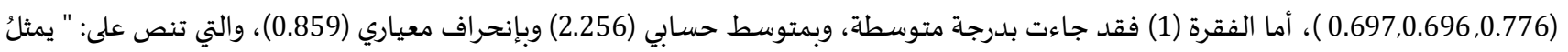

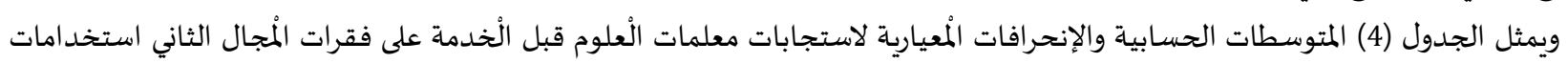
النّموذج الْعلمي استنساخ لشيء ما ". النّموذج الْعلمي. 
جدول (4): المتوسطات الحسابية والانحر افات المعيارية لاستجابات معلمات العلوم قبل الخدمة على فقرات المجال الثاني استخدامات النموذج العلمي

\begin{tabular}{|c|c|c|c|c|}
\hline الترتيب & الانحراف المعياري & المتوسط الحسابي & مجالات المقياس & الرقم \\
\hline 4 & 0.633 & 2.589 & يستخدم النموذج العلمي كمعيار او مرجع يمكن اتباعه . & 1 \\
\hline 1 & 0.438 & 2.833 & يستخدم النموذج العلمي لتمكين الشخص من تصور الظاهرة . & 2 \\
\hline 3 & 0.539 & 2.756 & يستخدم النموذج العلمي كوسيلة للدعم والإبداع ،وتخيل سياقات جديدة روخلق أفكار & 3 \\
\hline \multirow[t]{2}{*}{2} & 0.525 & 2.782 & يستخدم النموذج العلمي كطريقة لفهم أو شرح شيء ما. ج & 4 \\
\hline & 0.534 & 2.740 & المجموع & \\
\hline
\end{tabular}

نلاحظ من الجدول (4) أن معرفة معلمات العلوم قبل الخدمة بمجال استخدامات النموذج العلمي جاء بمستوى مرتفع، حيث بلغ المتوسط

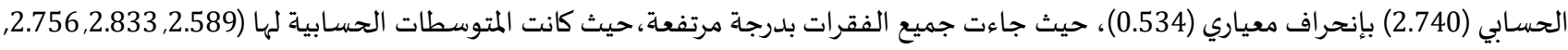

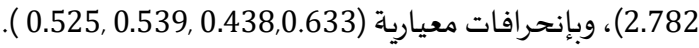

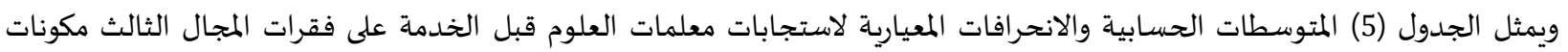
النموذج العلمي.

جدول (5): المتوسطات الحسابية والانحر افات المعيارية لاستجابات معلمات العلوم قبل الخدمة على فقرات المجال الثالث مكونات النموذج العلهي

\begin{tabular}{|c|c|c|c|c|}
\hline الترتيب & الانحراف المعياري & المتوسط الحسابي & مجالات المقياس & الرقم \\
\hline 4 & 0.659 & 2.487 & يمثل النموذج العلمي الاشياء. & 1 \\
\hline 3 & 0.678 & 2.512 & يمثل النموذج العلمي ما يحدث في نظام معين. & 2 \\
\hline 2 & 0.590 & 2.589 & يصف النموذج العلمي سلوك كائن أو عملية. & 3 \\
\hline 1 & 0.644 & 2.641 & يمثل النموذج العلمي فكرة او صوره ذهنية متخيلة. & 4 \\
\hline & 0.643 & 2.557 & المجموع & \\
\hline
\end{tabular}

نلاحظ من الجدول (5) أن معرفة معلمات العلوم قبل الخدمة بمجال مكونات النموذج العلمي جاء بمستوى مرتفع، حيث بلغ المتوسط الحسابي

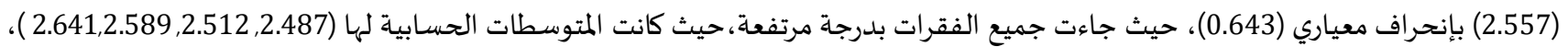
وبإنحرافات معيارية (0.644,0.590,0.678,0.659 ). ويمثل الجدول (6) المتوسطات الحسابية والإنحرافات المعيارية لاستجابات معلمات الْعلوم قبل الخدمة على على فقرات المجال الرابع التمييز . جدول (6): المتوسطات الحسابية والإنحر افات الْمعيارية لاستجابات معلمات الْعلوم قبل الْخدمة على فقرات المجال الر ابع التمييز

\begin{tabular}{|c|c|c|c|c|}
\hline الترتيب & الانحراف المعياري & 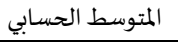 & مجالات المقياس & الرقم ل ت الرقم \\
\hline 2 & 0.771 & 2.230 & هناك نموذج علمي صحيح واحد فقط لظاهرة معينة . & 1 \\
\hline 3 & 0.763 & 2.166 & يتم اعتماد نموذج علمي واحد فقط من عدة نماذج متاحة للظاهرة. & 2 \\
\hline \multirow[t]{3}{*}{1} & 0.693 & 2.320 & يتم اعتماد نموذج علمي واحد فقط للظاهرة من عدة نماذج مختلفة نتجت عن التطور & 3 \\
\hline & & & 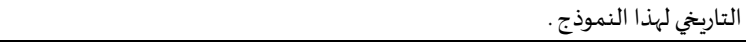 & \\
\hline & 0.742 & 2.238 & المجموع & \\
\hline
\end{tabular}

نلاحظ من الجدول (6) أن معرفة معلمات العلوم قبل الخدمة بمجال التمييز جاء بمستوى متوسط، حيث بلغ المتوسط الحسابي (2.238)

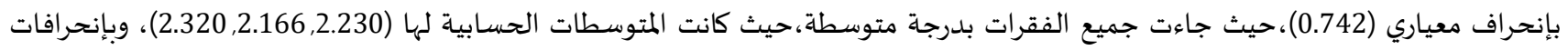
معيارية (0.693, 0.763,0.771). ويمثل الجدول (7) المتوسطات الحسابية والانحرافات المعيارية لاستجابات معلمات العلوم قبل الخدمة على فقرات المجال الخامس الثبات والاستقرار.

جدول (7): المتوسطات الحسابية والانحر افات المعيارية لاستجابات معلمات العلوم قبل الخدمة على فقرات المجال الخامس الثبات والاستقرار

\begin{tabular}{|c|c|c|c|c|}
\hline الترتيب & الانحراف المعياري & المتوسط الحسابي & مجالات المقياس & الرقم \\
\hline 4 & 0.848 & 1.820 & لا يمكن تغيير النموذج العلمي. & 1 \\
\hline 3 & 0.656 & 2.564 & يمكن تغيير النموذج العلمي عندما يتم تحديد المشاكل المرتبطة بطبيعة النموذج. & 2 \\
\hline 2 & 0.573 & 2.666 & يمكن تغيير النموذج العلمي عندما يتم تحديد المشاكل المرتبطة باستخداماته. & 3 \\
\hline \multirow[t]{2}{*}{1} & 0.474 & 2.730 & يمكن تغيير النموذج العلمي عندما يتم تحديد المشاكل المرتبطة بكفاءته التوضيحية. & 4 \\
\hline & 0.638 & 2.445 & المجموع & \\
\hline
\end{tabular}

نلاحظ من الجدول (7) أن معرفة معلمات العلوم قبل الخدمة بمجال الثبات والاستقرار جاء بمستوى مرتفع، حيث بلغ المتوسط الحسابي (2.445) بإنحراف معياري (0.638)،حيث جاءت الفقرات (4.3.2 ) بدرجة مرتفعة، وبمتوسطات حسابية (2.564, 2.666, 2.730)، وبإنحرافات معيارية 
(0.474,0.573, 0.656، أما الفقرة (1) فقد جاءت بدرجة متوسطة، وبمتوسط حسابي (1.820) وبإنحراف معياري (0.848)، والتي تنص على: " لا يمكن تغيير النموذج العلمي ". ويمثل الجدول (8) المتوسطات الحسابية والانحرافات المعيارية لاستجابات معلمات العلوم قبل الخدمة على فقرات المجال السادس التنبؤ.

\begin{tabular}{|c|c|c|c|c|}
\hline الترتيب & الانحراف الممعياري & المتوسط الحسابي & مجالات المقياس & الرقم \\
\hline 2 & 0.656 & 2.564 & يمكن استخدام النموذج العلمي لعمل تنبؤات حول السلوك أو الخصائص. & 1 \\
\hline 1 & 0.626 & 2.628 & يمكن ان يستخدم النموذج العلمي للتنبؤ وشرح كيفية حدوث ظاهرة مختلفة. & 2 \\
\hline 1 & 0.583 & 2.628 & يمكن للشرح القائم على النموذج العلمي ان يتنبأ بإمكانية تغيير عنصر أو أكثر من مكونات & 3 \\
\hline
\end{tabular}

نلاحظ من الجدول (8) أن معرفة معلمات العلوم قبل الخدمة بمجال التنبؤ جاء بمستوى مرتفع، حيث بلغ المتوسط الحسابي (0.621) (2.606) بإنحراف

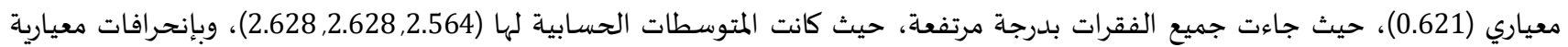

(0.583, 0.626,0.656)

ويمثل الجدول (9) المتوسطات الحسابية والانحرافات المعيارية لاستجابات معلمات العلوم قبل الخدمة على فقرات المجال السابع الاعتماد. جدول (9): المتوسطات الحسابية والانحر افات المعيارية لاستجابات معلمات العلوم قبل الخدمة على فقرات المجال السابع الاعتماد

\begin{tabular}{|c|c|c|c|c|}
\hline 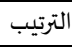 & 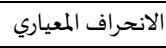 & 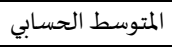 & 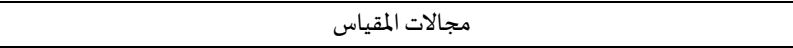 & 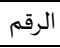 \\
\hline 2 & 0.614 & 2.576 & يمكن للفرد ان ينتج نموذجًا ويصل إلى استنتاجاته الخاصة حول شيء ما. & 1 \\
\hline 3 & 0.675 & 2.564 & يمكن لمجموعة في المجتمع ان تنتج نموذجا, وقد يمثل هذا النموذج وجهات النظر المقبولة في & 2 \\
\hline 1 & 0.566 & 2.602 & يمكن لمجتمع العلماء انتاج النماذج العلمية المثبتة نسبيا . & 3 \\
\hline & 0.618 & 2.580 & المجموع & \\
\hline
\end{tabular}

نلاحظ من الجدول (9) أن معرفة معلمات العلوم قبل الخدمة لمجال الاعتماد جاء بمستوى مرتفع، حيث بلغ المتوسط الحسابي (2.580)

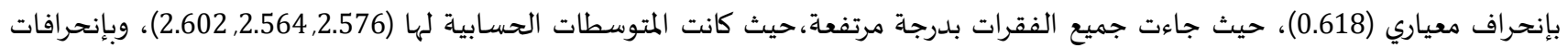

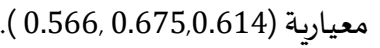
ويمثل الجدول (10) المتوسطات الحسابية والانحرافات المعيارية لاستجابات معلمات العلوم قبل الخدمة على مجالات النموذج العلمي السبعة.

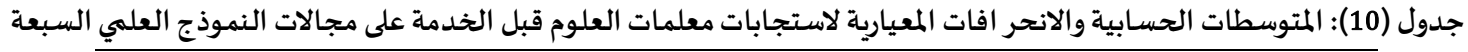

\begin{tabular}{|c|c|c|c|}
\hline الترتيب & الانحراف المعياري & المتوسط الحسابي & المجال \\
\hline 6 & 0.757 & 2.375 & طبيعة النموذج العلمي \\
\hline 1 & 0.534 & 2.740 & استخدامات النموذج العلمي \\
\hline 4 & 0.643 & 2.557 & مكونات النموذج العلمي \\
\hline 7 & 0.742 & 2.238 & التمييز \\
\hline 5 & 0.638 & 2.445 & الثبات والاستقرار \\
\hline 2 & 0.621 & 2.606 & التنبؤ \\
\hline 3 & 0.618 & 2.580 & الاعتماد \\
\hline & 0.650 & 2.506 & الكلي \\
\hline
\end{tabular}

نلاحظ من الجدول (10) أن مجال استخدامات النموذج العلمي جاء في المرتبة الأولى بمستوى مرتفع، حيث بلغ متوسطه الحسابي (2.740)

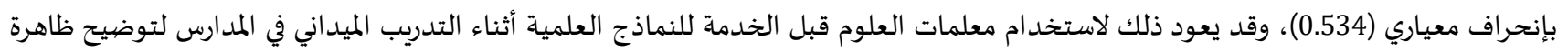
علمياة ما، أو لتوضيح مفهوم أو عملية .

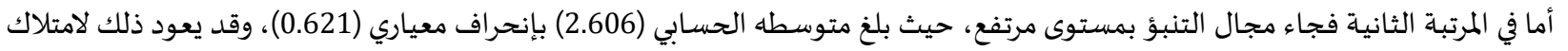

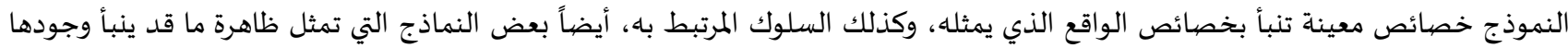
بشرح ظاهرة مختلفة، فالنموذج الذي يمثل ظاهرة الخسوف، قد ينبأ بظاهرة مختلفة وهي الكسوف نتيجة بعض التغييرات في هذا النموذج، ونتيجة

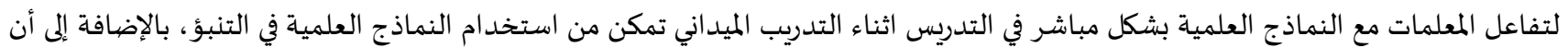
التنبؤ أحد أهداف العلم، وأيضاً أحد عمليات العلم التي تم تدريب المعلمات عليها أثناء دراسة مقرر طرق تدريس العلوم في الدبلوم التربوي. 
أما في المرتباة الثالثة فجاء مجال الاعتماد بمستوى مرتفع، حيث بلغ متوسطه الحسابي (2.557) بإنحراف معياري (0.618)، قد يعود ذلك إلى

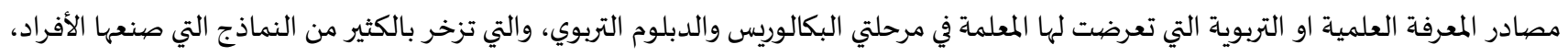

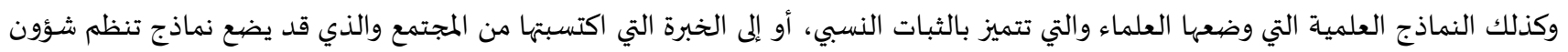
الحياة أو تمثل آراء أو افكار معينة. أما في المرتبة الرابعة فجاء مجال مكونات او النمار معينه، النموذج العلمي بمستوى مرتفع، حيث بلغ متوسطه الحسابي (2.580) بإنحراف معياري (0.643)، وقد

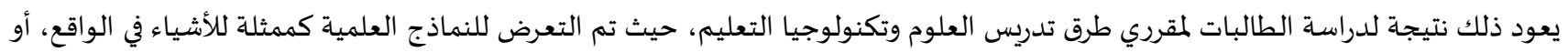

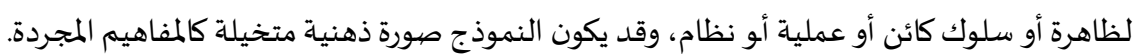
أما في المرتبة الخامسة فجاء مجال الثبات والاستقرار بمستوى مرتفع، حيث بلغ متوسطه الحسابي (2.445) بإنحراف معياري (0.638)، وقد يعود

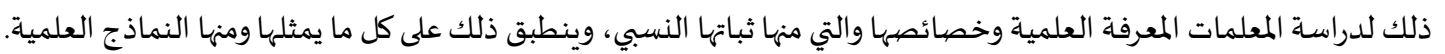

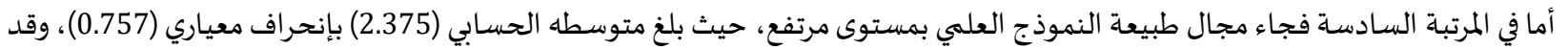

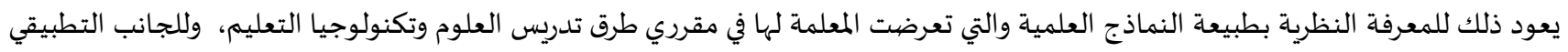

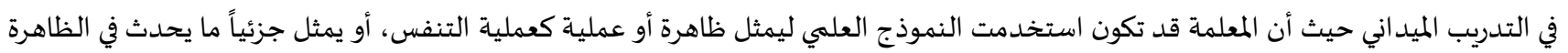
كعملية الشهيق أو الزفير. أما في المرتبة السابعة فجاء مجال التمييز بمستوى متوسط,حيث بلغ متوسطه الحسابي (2.238) بإنحراف معياري (0.742)، وقد يعود ذلك إلى

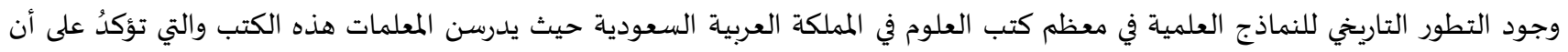

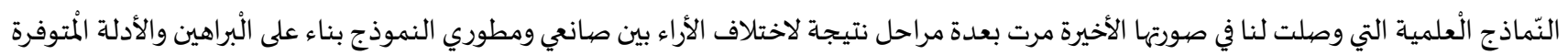

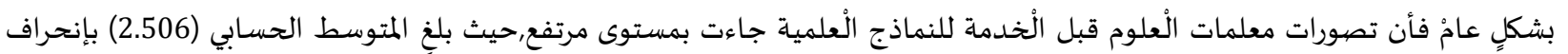

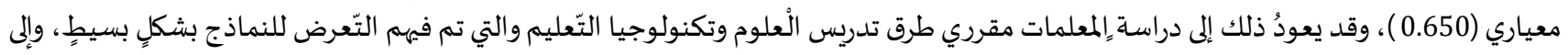

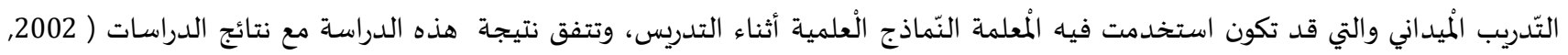

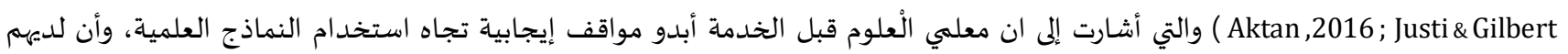
معرفة نظرية بالنماذج، ووعي بقيمة النماذج في تعلم العلوم .

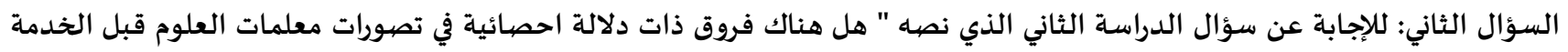

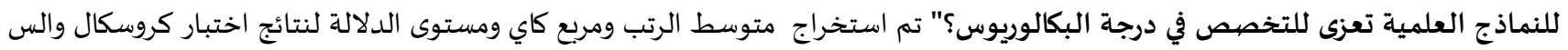
لأثر التخصص على استجابات معلمات العلوم قبل الخدمة على فقرات مقياس النماذج العلمية، كما هو موضح في الجدول(11).

\begin{tabular}{|c|c|c|c|c|c|c|}
\hline مستوى الدلالة & درجة الحرية & مريع كاي & متوسط الرتب & العدد & التخصص & المقياس \\
\hline \multirow[t]{3}{*}{0.159} & 2 & 3.680 & 45.25 & 22 & كيمياء & مقياس النماذج \\
\hline & & & 34.059 & 34 & احياء & العلمية \\
\hline & & & 42.159 & 22 & فيزياء & \\
\hline
\end{tabular}

يتضح من الجدول (11) عدم وجود فروق ذات دلالة احصائية عند مستوى الدلالة (0.05 م) بين متوسطات الرتب لاستجابات معلمات العلوم

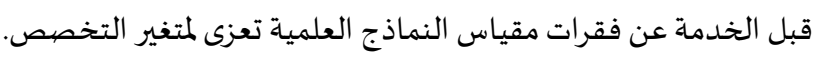

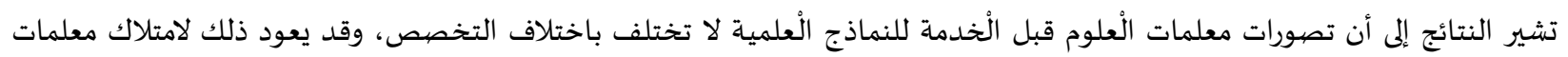

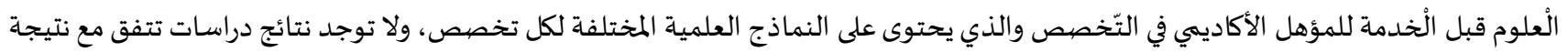

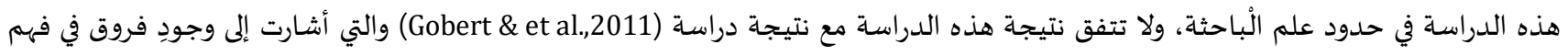

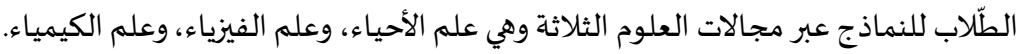




$$
\begin{aligned}
& \text { في ضوء نتائج الدراسـة الحالية تقترح الباحثة إجراء المزيد من البحوث والدراسـات في المجالات التالية: }
\end{aligned}
$$

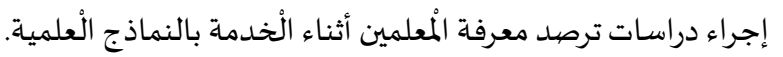

$$
\begin{aligned}
& \text { إجراء دراسات ترصد قدرة الْمعلمين قبل الْخدمة على تقييم النماذج العلمية المعدة من قبل الطلبة. } \\
& \text { إجراء دراسات ترصد قدرة الْمعلمين أثناء الْخدمة على تقييم النّماذج الْعلمية الْمعدة من قبل الطلبة. } \\
& \text { إجراء دراسات ترصد قدرة الطلبة على بناء النماذج العلمية. }
\end{aligned}
$$

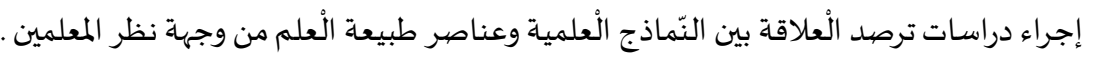

1. AAAS (American Association for the Advancement of Science). (1993). Benchmarks for science literacy. New York, NY: Oxford University Press.

2. Aktan,M.(2013). Pre-service science teachers' views and content knowledge about models and modeling. Education and Science, 38(168).

3. Aktan,M.(2016). Pre-service science teachers' perceptions and attitudes about the use of models. Journal of Baltic Science Education, 15(1).

4. Bolacha, E., Moita de Deus, H., Fonseca, P.E. (2012.). The concept of analogue modelling in Geology: An approach to mountain building. E-Book Proceedings of the ESERA 2011 Conference, Lyon, France, 7.

5. Boulter, C. J., \& Gilbert, J. K. (2000). Challenges and opportunities of developing models in science education. International Handbook of Science Education, 22(6):343-362.

6. Cho,E., Choi,J.\& Choe,S .(2017). An investigation in to the secondary science teachers' perceptions on models and modeling. ESERA Conference. Dublin City University. Dublin, Ireland.21st- 25th August.

7. Danusso, L., Testa, I., \& Vicentini, M. (2010). Improving prospective teachers' knowledge about scientific models and modelling: Design and evaluation of a teacher education intervention. International Journal of Science Education, 32 (7): 871-905, https://doi.org/10.1080/09500690902833221.

8. Giere, R.N., (2004). How Models are used to represent reality. Philosophy of Science, 71(5): 742-752, https://doi.org/10.1086/425063.

9. Gilbert, J. K., \& Boulter, C. J. (1998). Learning science through models and modelling. international Handbook of Science Education, 32(3): 53-66, https://doi.org/10.1007/978-94-011-4940-2_4.

10. Gilbert, S. W., \& Ireton, S. W. (2003). Understanding models in earth and space science. Arlington, VA: NSTA Press

11. Gobert, J.D., Buckley, B. C (2000). Introduction to Model-based Teaching and Learning in Science Education. International Journal of Science Education, 22(9): 891-894, https://doi.org/10.1080/095006900416839.

12. Gobert, J., ODwyer, L., Horwiz, P., Buckley, B., Levy,S.\& Wilensky,U. (2011). Examining the relationship between students' epistemologies of models and conceptual learning in three science domains: biology, physics \& chemistry. International Journal of Science Education, 33(55): 653-648, https://doi.org/10.1080/09500691003720671.

13. Grosslight L., Unger C., Jay E. \& Smith C., (1991), Understanding models and their use in science: conceptions of middle and high school students and experts. Journal of Research in Science Teaching, 28(9): 799-822, https://doi.org/10.1002/tea.3660280907.

14. Hahn, L. L., \& Gilmer, P. J. (2000). Transforming pre-service teacher education programs with science research experiences for prospective science teachers. Paper presented at the annual meeting of the Southeastern Association for the Education of Teachers in Science, Auburn, AL.

15. Halloun, I.A., (2007). Mediated modeling in Science Education. Science Education, 16(7-8): 653-697, https://doi.org/10.1007/s11191-006-9004-3.

16. Harrison, A. G., \& Treagust, D. F. (2000). Learning about atoms, molecules and chemical bonds: A case study of multiplemodel use in grade 11 chemistry. Science Education, 84(3): 352-381, https://doi.org/10.1002/(sici)1098237x(200005)84:3\%3C352::aid-sce3\%3E3.0.co;2-j.

17. Henze, I., Van Driel, J. H., \& Verloop, N. (2008). Development of experienced science teachers' pedagogical content knowledge of models of the solar system and the universe. International Journal of Science Education, 30 (10): 1321-1342, https://doi.org/10.1080/09500690802187017.

18. Jee, B.D., Uttal, D.H., Gentner, D., Manduca, C., Shipley, T.F., Tikoff, B., Ormand, C.J. \& Sageman, B., (2010). Commentary: Analogical thinking in geoscience education. Journal of Geoscience Education, 58(1): 2-13, https://doi.org/10.5408/1.3544291.

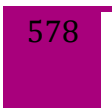

المجلة الدولية للدراسات التربوية والنفسية- المجلد9، العدد2- 2021، ص: 569-580 
19. Justi, R., (2009). Learning how to model in science classroom: Key teacher's role in supporting the development of students'modelling skills. Educación Química, 20(1): 32-40, https://doi.org/10.1016/s0187-893x(18)30005-3.

20. Justi, R. S., \& Gilbert, J. K. (2002). Science teachers' knowledge about and attitudes towards the use of models and modelling in learning science. International Journal of Science Education, 24(12): 1273-1292, https://doi.org/10.1080/09500690210163198.

21. Justi, R. S., \& Van Driel, J. H. (2006). The use of the interconnected model of teacher professional growth for understanding the development of science teachers' knowledge on models and modelling. Teaching and Teacher Education, 22 (4): 437450, https://doi.org/10.1016/j.tate.2005.11.011.

22. Koponen, I.T. (2007). Models and modelling in Physics Education: Acritical re-analysis of philosophical underpinnings and suggestions for revisions. Science Education. 16(7-8), 751-773, https://doi.org/10.1007/s11191-006-9000-7.

23. Magnani, L., \& Nersessian, N. J. (2002). Model-based reasoning: science, technology, values. New York, NY: Kluwer Academic/Plenum Publishers.

24. Mahr, B. (2012). On the epistemology of models. In G. Abel \& J. Conant (Eds.), Rethinking epistemology. Berlin: Walter de Gruyter.

25. Mugaloglu, E., Erduran, S \& Dagher, Z, (2017). Preservice teachers' perceptions of models as scientific practices. ESERA Conference. Dublin City University. Dublin, Ireland.21st- 25th August.

26. National Research Council. (1996). National Science Education Standards. Washington, DC: National Academy Press.

27. National Research Council]. (2007). Status of Pollinators in North America. The National Academies Press, Washington, D.C. USA

28. Nelson,M. \& Davis, E. (2012). Preservice elementary teachers' evaluations of elementary students' scientific models: An aspect of pedagogical content knowledge for scientific modeling, International Journal of Science Education, 34(12): 19311959, https://doi.org/10.1080/09500693.2011.594103.

29. Ogan-Bekiroglu, F. (2007). Effects of model-based teaching on pre-service physics teachers' conceptions of the Moon, Moon phases and other lunar phenomena. International Journal of Science Education, 29(5): 555-593, https://doi.org/10.1080/09500690600718104

30. OGAN-BEKIROGLU, F.\& ARSLAN-BUYRUK, A. (2018). Examination of pre-service physics teachers' epistemologies of scientific models and their model formation during model-based inquiry process. Asia-Pacific Forum on Science Learning and Teaching, 19(1): 1-23.

31. Oh, P. S., \& Oh, S. J. (2011). What teachers of science need to know about models: An overview? International Journal of Science Education, 33 (8): 1109-1130.

32. Passmore, C., Svoboda Gouvea, J., \& Giere, R. N. (2014). Models in science and in learning science: focusing scientific practice on sense-making. In M. R. Matthews (Ed.), International handbook of research in history, philosophy and science teaching, 107(22): 1171-1202.

33. Reinisch, B. \& Krüger, D. (2016). Preservice biology teachers' conceptions about the tentative nature of theories and models in biology. Education and Science, 48(1): 71-103, https://doi.org/10.1007/s11165-016-9559-1.

34. Rutherford, F. J., \& Ahlgren, A. (1990). Science for all Americans. New York: Oxford University Press.

35. Schwarz, C., Reiser, B., Davis, E., Kenyon, L., Acher, A., Fortus, D., Schwatz, Y., Hug, B., \& Krajcik, J. (2009). Developing a learning progression for scientific modeling: Making scientific modeling accessible and meaningful for learners. Journal of Research in Science Teaching, 46(6): 632-654, https://doi.org/10.1002/tea.20311.

36. Svoboda, J., \& Passmore, C. (2013). The strategies of modeling in biology education. Science Education, 22(1): 119-142, https://doi.org/10.1007/s11191-011-9425-5.

37. Torres, J. \& Vasconcelos,C. (2014). Models and modelling in biology and geology teachers' initial training. Geological Communications. 101(3): 1391-1394. 
المجلة الدولية للدراسـات التربوية والنفسية

International Journal of Educational \& Psychological Studies (EPS)

Journal Homepage: https://www.refaad.com/views/EPSR/Home.aspx

ISSN: 2520-4149 (Online) 2520-4130 (Print)

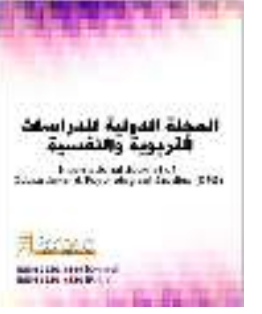

\section{Pre-service science teachers' perceptions of scientific models}

\section{Sanaa Mohamed Abu Athera}

Associate Professor, Curricula and Methods of Teaching Sciences, College of Education, Taif University, KSA sa37003@yahoo.com

Received : 18/6/2020 Revised : 30/6/2020 Accepted : 22/7/2020 DOI : https://doi.org/10.31559/EPS2021.9.2.13

Abstract: The aim of this study was to identify the perceptions of Pre-service science teachers for scientific models, And the sample of the study consisted of (78) Pre-service science teachers enrolled in the educational diploma program at Taif University for the first semester of 2018-2019. In order to achieve the purpose of the study, the researcher used the descriptive approach. A questionnaire was designed as a tool for applying the study, The results of the study showed that the perceptions of the Pre-service science teachers of the scientific models came at a high level, and the results indicated that there were no statistically significant differences at the level $(\alpha \leq 0.05)$ Between the arithmetic averages of pre-service science teachers' responses to the scales of the scientific models due to the specialization variable, The study recommended directing the training programs for teachers in the education sector to prepare training programs on scientific models and how to build and evaluate them.

Keywords: perceptions, science teachers; pre-service; scientific models. 